Food, Dairy and Home Economic Research

\title{
UTILIZATION OF BARLEY MALT AS A PARTIAL REPLACEMENT OF WHEAT FLOUR IN BISCUITS INDUSTRIES
}

\author{
Mohamed R.E. El-Hadary ${ }^{2 *}$, Ghada M. El-Arby ${ }^{2}$, M.M. Abdel-Hady ${ }^{1}$ and S.M. Abo-Elmaaty ${ }^{2}$ \\ 1. Food Technol. Res. Inst., Egypt \\ 2. Food Sci. Dept., Fac. Agric., Zagazig Univ., Egypt
}

Received: 05/11/2017 ; Accepted: 21/11/2017

\begin{abstract}
The current study aimed to utilize hulled and naked barley malt as a substitute supplementation of wheat biscuits. Physicochemical properties of hulled and naked barley malt were studied. Wheat flour was substituted by 25,30 and $35 \%$ of hulled and naked barley malt. The obtained results declared that the rheological characteristics of mixtures dough were altered by increasing the ratio of hulled and naked malt barley. Substitution with 25 and 30\% hulled and naked barley malt had the best results which were relatively close to that of control sample. The physicochemical properties of biscuits enriched by hulled and naked barley malt that characterized by increasing both density, texture, water holding capacity and oil holding capacity. Chemical composition of enriched biscuits, for moisture, ash, dietary fiber, protein and minerals content were increased while fat and available carbohydrate content lowered. Sensory evaluation showed that substitution with $25 \%$ and $30 \%$ hulled and naked barley malt had the best sensory characteristics, and increased its content of dietary fiber and $\beta$-Glucan.
\end{abstract}

Key words: Barley malt, $\beta$-Glucan, biscuits, wheat flour.

\section{INTRODUCTION}

In the last decades the search for functional foods has been widely encouraged by food companies. Consumers demand of new food products not only to satisfy a physiological need but also to have healthy food with necessary nutrients to prevent nutrition-related diseases and to improve physical and mental health. In this regard, a close relation between nutrition and health has been established and functional foods containing ingredients with a specific health benefit were technologically developed as reported by Niva (2007).

Barley (Hordeum vulgare L.) is an ancient and important cereal grain crop. According to FAO (2014), the world production of barley is about 144.5 milion ton, with about 102.244 thousand ton annually Egyptian production. In recent years, about two-thirds of the barley crop production has been used for feed, one-third for

* Corresponding author: Tel. : +201150664523

E-mail address: agronomohamad@gmail.com malting and about $2 \%$ for food directly. However, throughout its history, it has remained a major food source for some cultures principally in Asia and Northern Africa (Newman and Newman, 2006). Barley was recognized early as a hearty tasting, high-energy food. For example, the Roman gladiators were known as "hordearii" or "barley men" relative to eating barley providing them strength and stamina. While in Middle Eastern and North African countries, barley is pearled, ground, and used in soups, flat bread making and porridge preparation (Sullivan et al., 2012). Whole barley grain consists of about $65-68 \%$ starch, $10-17 \%$ protein, $4-9 \% \beta$-glucan, $2-3 \%$ free lipids and $1.5-2.5 \%$ minerals (Izydorczyk et al., 2000 ; Quinde et al., 2004).

The major advantage of incorporating barley into various food products and the consumption of its stems is for thepotential health benefits. The effectiveness of barley $\beta$-glucans, and glycemic index in barley food products in lowering blood cholesterol was reported 
(Meiselman, 2016). Barley is a rich source of tocols, including tocopherols and tocotrienols, which are known for reducing serum low density lipoprotein cholesterol (LDL-C) through their antioxidant action (Pins and Kaur, 2006). The predominant food product of barley is malt which is mainly used in the brewing industry. Malt is the product resulted from controlled germination, drying and milling of barley. Barley malt was used as food ingredient for its wide range of attributes and benefits. It may be used as a flavouring agent or flavouring enhancer, source of nutrients and fermentable sugars and natural colouring agent or as a colour enhancer through browning reactions. Barley malt also find application in a wide range of health foods including crisp breads, biscuits, breads, breakfast cereals, confectionery, baby foods, milk drinks, pet foods, sauces, soups and seasonings (Sullivan et al., 2012). The largest use was in fermented bakery products as a source of soluble sugars, protein and amylases to promote the activity of yeast resulting in good bread texture and higher loaf volume, good flavour and colour of the end baked products (Mahdi et al., 2008).

The aim of this study was to evaluate the physiochemical properties of naked and hulled barley malt, use it as wheat flour substitute with different levels $(25 \%, 30 \%$ and $35 \%)$ in biscuits manufacturing and evaluate the effect of these substitution levels on the quality attributes of the end product (biscuit).

\section{MATERIALS AND METHODS}

\section{Materials}

Raw hulled and naked barley grains were obtained from Agriculture Research Center Giza, Egypt, while wheat flour $72 \%$ extraction, margarine, vanilla, sugar, skim milk powder, ammonium bicarbonate and baking powder were obtained from local market, Zagazig, Sharkia Governorate, Egypt. All chemicals used in this study were analytical grade and purchased from El-Gomhoria Co., Zagazig, Sharkia Governorate, Egypt.

\section{Methods}

\section{Malt Preparation}

The method described by Mareček et al. (2016) was used for malt preparation. Malt was obtained from controlled germination of barley grains, the germinated grains were subsequently dried at $45^{\circ} \mathrm{C} / 72 \mathrm{hrs}$., and ground and sieved using a $2.5-\mathrm{mm}$ sieve.

\section{Biscuits Preparation}

Biscuit samples (control and with different substitution levels) were prepared according to the standard recipe described in Table 1 except that in case of biscuits with malt addition, a partial replacement of wheat flour $72 \%$ with levels; of $25 \%, 30 \%$ and $35 \%$ of malt was performed. Sugar, fat and vanillin were creamed in mixing bowel for $15 \mathrm{~min}$., ammonium bicarbonate and water were added and mixed for $2 \mathrm{~min}$. Wheat flour (in case of control sample) and malt and substituted wheat flour (in case of biscuits with different substitution levels) were added to the mixture with skim milk powder and baking powder. The mixture was subsequently mixed until getting homogeneous dough. The later was removed from mixing bowl, laminated, sheeted and shaped by cutting machine. Baking was carried out at $250^{\circ} \mathrm{C}$ for $10 \mathrm{~min}$. After baking biscuits were being cooled at room temperature and then warped tightly by aluminum foil and kept for sensory evaluation as reported by Mesías et al. (2015).

\section{Assessments}

\section{Proximate chemical composition}

The chemical composition of different biscuit samples; moisture, ash, crude protein, fiber, mineral and crude lipid contents (\%) was determined according to the methods described by AOAC (2005), while total carbohydrate content was calulated by difference. However, $\beta$-glucan content was determined according to method described by AOAC (1995) at the Central Laboratory, Faculty of Agriculture, Zagazig University, Zagazig, Sharkia Governorate, Egypt.

\section{Physical properties of biscuit \\ Hardness Determination}

The hardness $(\mathrm{N})$ of different biscuit samples was determined at Food Technology Research Institute, Giza, Egypt, according to Mesías et al. (2016) using Texture Analyzer (Texture Technologies Corporation, USA) equipped with a $50 \mathrm{~kg}$ load cell, a probe (Warnere Bratzcer, 
Table 1. The recipe used for biscuits making

\begin{tabular}{lccccccc}
\hline Ingredient & \multicolumn{7}{c}{ Amount (g) } \\
\cline { 2 - 8 } & $\begin{array}{c}\text { Standard } \\
\text { wheat flour } \\
(\mathbf{7 2 \% )}\end{array}$ & \begin{tabular}{c} 
Substituted wheat flour by malt powder \\
\cline { 3 - 8 }
\end{tabular} & $\begin{array}{c}\text { Hulled barley malt } \\
\text { powder }\end{array}$ & \multicolumn{3}{c}{$\begin{array}{c}\text { Naked barley malt } \\
\text { powder }\end{array}$} \\
\cline { 3 - 8 } & & $\mathbf{2 5 \%}$ & $\mathbf{3 0 \%}$ & $\mathbf{3 5 \%}$ & $\mathbf{2 5 \%}$ & $\mathbf{3 0 \%}$ & $\mathbf{3 5 \%}$ \\
\hline Wheat flour & 100 & 75 & 70 & 65 & 75 & 70 & 65 \\
Malt powder & 0 & 25 & 30 & 35 & 25 & 30 & 35 \\
Margarine & 24 & 24 & 24 & 24 & 24 & 24 & 24 \\
Sugar & 30 & 30 & 30 & 30 & 30 & 30 & 30 \\
Vanilla & 0.1 & 0.1 & 0.1 & 0.1 & 0.1 & 0.1 & 0.1 \\
Ammonium bicarbonate & 1.5 & 1.5 & 1.5 & 1.5 & 1.5 & 1.5 & 1.5 \\
Skim milk powder & 1.0 & 1.0 & 1.0 & 1.0 & 1.0 & 1.0 & 1.0 \\
Baking powder & 0.8 & 0.8 & 0.8 & 0.8 & 0.8 & 0.8 & 0.8 \\
Water & 12.0 & 12.0 & 12.0 & 12.0 & 12.0 & 12.0 & 12.0 \\
\hline
\end{tabular}

HDP/BSK knife model) with a compression speed of $1 \mathrm{~mm}$. $\mathrm{s}^{-1}$ and a distance prolongation of $10 \mathrm{~mm}$. The force at the first major drop in the forced formation curve $\left(\mathrm{F}_{\max }\right)$ and deformation at maximum force were obtained for 4 replicates for each sample.

\section{Density measurement}

The density of different biscuit samples was determined using Archimedes (buoyancy) method according to Amiri et al. (2017). Was determined according to the following: Density $=$ mass $/$ volume $\left(\mathrm{g} / \mathrm{cm}^{-3}\right)$

\section{Colour measurement}

The colour of biscuit crust $r$ was measured according to Zenoozian et al. (2007) using a Minolta colorimeter (Model CR- 400, Konica Minolta Sensing, Inc., Osaka, Japan) based on three colour coordinates; $\mathrm{L}^{*}$ (Lightness), a* (redness/ greenness), $\mathrm{b}^{*}$ (yellowness/blueness). The measurement for each sample was replicated and the average value was recorded for each colour parameter.

\section{Water Holding Capacity}

Water Holding Capacity (WHC) was measured according to Chau and Huang (2003) with slight modification, one gram of wheat flour $72 \%$ and malt substituted wheat flour was well mixed with $20 \mathrm{ml}$ distilled water and allowed to stand $1 \mathrm{hr}$., at room temperature. The hydrated sample was centrifuged at $1500 \mathrm{rpm}$ for $10 \mathrm{~min}$. After centrifugation, the excess supernatant was carefully decanted. WHC was expressed as ml of retained water by $1 \mathrm{~g}$ dry basis of sample (ml.g).

\section{Oil Holding Capacity}

Oil Holding Capacity (OHC) was measured according to Garau et al. (2007) with slight modification. One gram of wheat flour $72 \%$ and malt substituted wheat flour was mixed with 20 $\mathrm{ml}$ corn oil and allowed to stand $1 \mathrm{hr}$., at room temperature; the sample was then centrifuged at $1500 \mathrm{rpm}$ for $10 \mathrm{~min}$. The excess oil was carefully decanted. WHC was expressed as $\mathrm{ml}$ of retained oil by $1 \mathrm{~g}$ dry basis of sample ( $\mathrm{ml} . \mathrm{g})$.

\section{Rheological Behavior}

Farinograph and extensograph of dough rheological properties were measured according to $\mathrm{AACC}$ (2007).

\section{Dough properties by farinograph}

Water absorption (\%), dough development (min), stability time ( $\mathrm{min}$ ) and dough weakening were determined by Brabender Farinograph (model 810114, Brabender, Duisburg, Germany) 
at Food Technology Research Institute Giza, Egypt.

\section{Dough properties by extensograph}

Dough extensibility E ( $\mathrm{mm})$, resistance to extension R (BU), Energy $\left(\mathrm{cm}^{2}\right)$ and proportional number $\mathrm{R} / \mathrm{E}$ were determined by Brabender Extensograph (model 860702, Brabender, Duisburg, Germany), Food Technology Research Institute Giza, Egypt.

\section{Sensory Evaluation}

Sensory evaluation was performed as described by Hooda and Jood (2005). Biscuit samples were presented as coded samples to ten member staff at food science department, Faculty of Agriculture, Zagazig University to evaluate the sensory attributes of the biscuits according to it's appearance, colour, taste, flavour and overall acceptability. The evaluation was based on hedonic scale of 1 to 9 point, where $(1=$ dislike extremely, $2=$ dislike very much, $3=$ dislike moderately, $4=$ dislike slightly, $5=$ neither like nor dislike, $6=$ like slightly, $7=$ like moderately, 8 , like very much, $9=$ like extremely).

\section{Statistical Analysis}

The obtained data were statistically analyzed by a statistical for social science package "SPSS" version 20 for Microsoft windows, SPSSInc according to Dominick and Derrick (2001).

\section{RESULTS AND DISCUSSION}

\section{Proximate Chemical Composition of Malt from Hulled and Naked Barley}

Hulled and naked barley malt were analyzed for moisture, crude protein, crude fiber, crude fat, total carbohydrate, ash, and $\beta$-glucan contents and the results are given in Table 2. The obtained results, at extremely same level of moisture content in both types of malt. Protein, ash and total carbohydrate contents in hulled barley malt were higher than in naked barley malt. On the other hand, naked barley malt had higher content of crude fat and crude fiber.

$\beta$-glucan, the major fiber constituents of barley, have been implicated in lowering plasma cholesterol, improving lipid metabolism, and reducing glycaemic index (Behall et al., 2004, 2005 and 2006; Steelea et al., 2013).

A considerable amount of $\beta$-glucan was found in both types of malt. Malt of hulled barley contained slightly higher level than other malt. These results are in general agreement with results obtained by Izydorczyk et al. (2000) and Quinde et al. (2004). They reported that whole barley grain consists of about 65$68 \%$ starch, $10-17 \%$ protein, $4-9 \% \beta$-glucan, $2-$ $3 \%$ free lipids and $1.5-2.5 \%$ ash.

Some of the minerals contents of malt were also shown in the same Table. The malt was analyzed for calcium, phosphorus, zinc, iron and selenium. The results declared that malt consider to be a good source for phosphorus, zinc, selenium, calcium and iron but lower in the other minerals as reported in USDA (2004). Calcium is required for formation and maintenance of bones and teeth thus, preventing osteoporosis. It is also needed for normal blood clotting and nervous function, the calcium content in hulled barley malt was higher than in malt naked barley by $24.59 \%$. The phosphorus content in hulled barley malt was higher than in naked barley malt by $13.54 \%$.

Iron is another essential element for almost all living organisms (Abbaspour et al., 2014), hulled barley malt had a double amount of iron that found in naked barley malt. Selenium content in hulled barley malt was higher than that found in naked barley malt, which contained 10.35 and $8.86 \mathrm{mg} / 100 \mathrm{~g}$, of this type, respectively.

\section{Water and Oil Holding Capacity of Substituted wheat flour by malt}

WHC and $\mathrm{OHC}$ of wheat flour $72 \%$ and substituted flour with malt from hulled and naked barley flour as well, was evaluated (Table 3). The obtained results showed that both WHC and OHC were increased, as general tendency, after the substitution. These properties were increased by increasing the level of malt addition regardless the barley variety; the high WHC and OHC were observed for wheat flour substitution by $35 \%$ as substitution level for the two barley varieties. WHC increased by $18 \%$ and $21 \%$ 
Table 2. Proximate chemical composition of malt from Hulled and Naked barley on wet weight basis

\begin{tabular}{lcc}
\hline Parameter & Hulled barley & Naked barley \\
\hline Moisture (\%) & $9.7 \pm 0.16$ & $9.7 \pm 0.12$ \\
Protein (\%) & $12.3 \pm 0.86$ & $11.9 \pm 0.89$ \\
Ash (\%) & $2.37 \pm 0.04$ & $1.63 \pm 0.05$ \\
Fat (\%) & $2.39 \pm 0.09$ & $3.1 \pm 0.097$ \\
Fiber (\%) & $19.5 \pm 0.30$ & $23.7 \pm 1.2$ \\
*Carbohydrate (\%) & $53.74 \pm 2.34$ & $49.97 \pm 1.181$ \\
B-glucan (\%) & $8.9 \pm 0.249$ & $8.2 \pm 0.125$ \\
Calcium (mg/100g) & 150.23 & 120.58 \\
Phosphorus (mg/100g) & 243.25 & 214.25 \\
Zinc (mg/100g) & 23.66 & 34.55 \\
Iron (mg/100g) & 7.87 & 3.67 \\
Selenium (mg/100g) & 10.35 & 8.86 \\
\hline
\end{tabular}

* Carbohydrates percentage was calculated by the difference.

while, $\mathrm{OHC}$ was increased by $11 \%$ and $7 \%$ with $35 \%$ of wheat flour substitution by hulled and naked barley malt, respectively compared to wheat flour $72 \%$. It is important to mention that the WHC of wheat flour substituted by naked barley malt was higher than those of wheat flour substituted by hulled barley malt. However, the $\mathrm{OHC}$ of the later was higher compared to that of wheat flour substituted by naked barley (Table 3). The increasing of WHC in substituted wheat flour compared to wheat flour $72 \%$ may related to the substitution of wheat flour by barley malt. However the high WHC of substituted wheat flour by naked barley malt may due to its high content of fiber $(23.7 \%)$ compared to those of hulled barley malt. The high OHC of substituted wheat flour by hulled barley malt can explain by its low fat content allowing more absorption of oil compared to naked barley malt which had high fat content decreasing more absorption of oil. These results concerning WHC are in agreement with the results reported by Izydorczyk et al. (2005).

\section{Rheological properties}

\section{Farinograph indices}

Farinograph measurements are summarized in Table 4. Results showed that the water absorption of dough was increased gradually from $57.4 \%$ of control to $59.4 \%$ and $62.5 \%$ at addition levels of $35 \%$ of hulled and naked barley malt, respectively. The obtained results showed that increasing the addition of malt of both types of barley more than $25 \%$ led to deleterious effect in dough characteristics. Farinogram indices like arrival time, development time and dough stability were lowered in 30 and $35 \%$ malt mixtures, so the degree of weakening effect (a degree of softening, the vertical space in BU between the end of farinogram after $12 \mathrm{~min}$. of its peak and the $500 \mathrm{BU}$ line) increased from 100 to reach $130 \mathrm{BU}$, at $35 \%$ naked barley.

\section{Extensograph results}

Results of extensograph parameters of wheat flour blended with 25,30 and $35 \%$ hulled and 
El-Hadary, et al.

Table 3. Water and oil holding capacity of substituted wheat flour by hulled and naked barley malt with different levels

\begin{tabular}{cccccccc}
\hline \multicolumn{9}{c}{ Substituted wheat flour } \\
\hline Property/ & Wheat flour & \multicolumn{3}{c}{ Hulled barley malt } & \multicolumn{3}{c}{ Naked barley malt } \\
\cline { 3 - 8 } sample & $\mathbf{( 7 2 \% )}$ & $\mathbf{2 5 \%}$ & $\mathbf{3 0 \%}$ & $\mathbf{3 5 \%}$ & $\mathbf{2 5 \%}$ & $\mathbf{3 0 \%}$ & $\mathbf{3 5 \%}$ \\
\hline WHC & $180.9 \pm 1.90$ & $186.2 \pm .95$ & $199.1 \pm 2.1$ & $213.5 \pm 2.1$ & $192.6 \pm 1.87$ & $205.1 \pm 2.28$ & $218.2 \pm 1.74$ \\
OHC & $171.2 \pm 1.86$ & $179.4 \pm 1.18$ & $183.7 \pm 1.5$ & $189.8 \pm 0.8$ & $176.8 \pm 0.82$ & $181.4 \pm 1.03$ & $183.2 \pm 1.79$ \\
\hline
\end{tabular}

WHC: Water holding capacity OHC: oil holding capacity

Table 4. Effect of wheat flour substituting by hulled and naked barley malt with different levels on farinograph dough characteristics

\begin{tabular}{lccccccc}
\hline & \multicolumn{7}{c}{ Substituted wheat flour } \\
\hline Dough properties & Wheat flour & \multicolumn{6}{c}{ Hulled barley } \\
\cline { 3 - 8 } & $\mathbf{( 7 2 \% )}$ & $\mathbf{2 5 \%}$ & $\mathbf{3 0 \%}$ & $\mathbf{3 5 \%}$ & $\mathbf{2 5 \%}$ & $\mathbf{3 0 \%}$ & $\mathbf{3 5 \%}$ \\
\hline Water absorption (\%) & 57.4 & 58.1 & 58.7 & 59.4 & 60.1 & 61.7 & 62.5 \\
Arrival time (min) & 1.5 & 1.0 & 1.0 & 1.0 & 1.0 & 1.0 & 0.5 \\
Dough development time (min) & 2.5 & 2.0 & 2.0 & 2.0 & 1.5 & 1.5 & 1.0 \\
Stability time (min) & 7.5 & 7.0 & 6.0 & 6.0 & 6.5 & 6.0 & 6.0 \\
Degree of softening (BU) & 100 & 100 & 120 & 125 & 100 & 120 & 130 \\
\hline
\end{tabular}

naked barley malt were given in Table 5. Results showed that elasticity, resistance to extension (R), of dough containing up to $25 \%$ hulled and naked barley malt was increased from $420 \mathrm{BU}$ for control to 450 and $390 \mathrm{BU}$, respectively. Increasing the malt added to the flour over that lowered the elasticity to about half of control. On the other hand, the addition of malt caused a gradual decrement in dough extensibility (E) with increasing the adding level of both types of malt.

The proportional number $(\mathrm{R} / \mathrm{E})$ is an overall index that indicates the effects of the treatments on the quality of dough. The results in Table 5 show that both types of malt and amount of malt affect the quality of dough. Addition of malt up to $25 \%$ in dough had an enhancer effect in dough quality while the higher concentrations from both types of malt showed defects in quality. Energy values of dough decreased by adding of either hulled or naked barley malt than the control sample.

The rheological results showed that the malt addition from both types of barley up to 25 and
$30 \%$ have potentialities to be used in supplementing flour for manufacture biscuit. On the other hand, increasing the supplementation will have deleterious effects on dough quality. However, it is a well known that weak flours are suitable for manufacture biscuit. These results are in agreement with Campos et al. (1997) and Skendi et al. (2009).

\section{Quality Attributes of Biscuit Manufactured Using Substituted Wheat Flour by Barley Malt}

\section{Chemical composition and nutrition value}

Chemical composition and nutrition value of biscuit manufactured using wheat flour $72 \%$ and substituted wheat flour by hulled and naked barley malt were determined. The obtained results show that moisture content of biscuit manufactured from substituted wheat flour by barley malt was higher than those manufactured from only wheat flour $72 \%$ under the same conditions of baking (Table 6). This phenomenon could be explained by the high fiber content found in barley malt regardless the barley type compared to wheat flour $72 \%$ allowing more 
Table 5. Effect of wheat flour substituting by hulled and naked barley malt with different levels on extensograph dough characteristics

Substituted wheat flour

\begin{tabular}{lccccccc}
\hline Dough property & $\begin{array}{c}\text { Wheat flour } \\
(\mathbf{7 2 \%})\end{array}$ & \multicolumn{3}{c}{ Hulled barley malt } & \multicolumn{3}{c}{ Naked barley malt } \\
\cline { 3 - 8 } & & $\mathbf{2 5 \%}$ & $\mathbf{3 0 \%}$ & $\mathbf{3 5 \%}$ & $\mathbf{2 5 \%}$ & $\mathbf{3 0 \%}$ & $\mathbf{3 5 \%}$ \\
\hline Elasticity R (BU) & 420 & 450 & 240 & 150 & 390 & 360 & 210 \\
Extensibility (BU) & 90 & 85 & 80 & 45 & 80 & 75 & 65 \\
P.N*(R/E) & 4.67 & 5.29 & 3.0 & 3.33 & 4.8 & 4.8 & 3.23 \\
Energy $\left(\mathbf{c m}^{2}\right)$ & 62 & 42 & 36 & 28 & 54 & 47 & 19 \\
\hline *P.N: Proportionyyyyyyyyyyyyy
\end{tabular}

* P.N: Proportional number

$\mathrm{R} / \mathrm{E}:($ elasticity/extensibility)

Table 6. Chemical and nutritional evaluation of biscuits supplemented by hulled and naked barley malt on wet weight basis

\begin{tabular}{lccccccc}
\hline Parameter & Control & \multicolumn{3}{c}{ Hulled barley } & \multicolumn{3}{c}{ Naked barley } \\
\cline { 3 - 8 } & & $\mathbf{2 5 \%}$ & $\mathbf{3 0 \%}$ & $\mathbf{3 5 \%}$ & $\mathbf{2 5 \%}$ & $\mathbf{3 0 \%}$ & $\mathbf{3 5 \%}$ \\
\hline Moisture (\%) & $8.1 \pm 0.27$ & $8.3 \pm 0.414$ & $8.5 \pm 0.68$ & $8.8 \pm 0.49$ & $8.4 \pm 0.39$ & $8.9 \pm 0.5$ & $9.2 \pm 0.58$ \\
Protein (\%) & $9.91 \pm 0.33$ & $10.6 \pm 0.22$ & $10.9 \pm 0.28$ & $11.3 \pm 0.16$ & $10.3 \pm 0.1$ & $10.8 \pm 0.5$ & $11.2 \pm 0.2$ \\
Fat (\%) & $26.9 \pm 0.47$ & $26.3 \pm 0.31$ & $25.1 \pm 0.51$ & $24.3 \pm 0.41$ & $26.6 \pm 0.2$ & $25.5 \pm 0.2$ & $24.9 \pm 0.1$ \\
Fiber (\%) & $0.89 \pm 0.061$ & $3.14 \pm 0.15$ & $3.59 \pm 0.16$ & $4.04 \pm 0.123$ & $3.77 \pm 0.06$ & $4.34 \pm 0.2$ & $5.02 \pm 0.2$ \\
Carbohydrate (\%) & $53.43 \pm 0.29$ & $50.65 \pm 0.87$ & $50.88 \pm 0.91$ & $50.46 \pm 0.15$ & $50.08 \pm 0.2$ & $49.53 \pm 0.5$ & $48.72 \pm 0.7$ \\
Ash (\%) & $0.77 \pm 0.01$ & $1.01 \pm 0.01$ & $1.03 \pm 0.21$ & $1.1 \pm 0.01$ & $0.85 \pm 0.01$ & $0.93 \pm 0.01$ & $0.96 \pm 0.01$ \\
Fe (mg/100g) & 4.38 & 5.27 & 5.44 & 5.62 & 4.72 & 4.78 & 4.86 \\
Zn (mg/100g) & 3.40 & 3.42 & 3.43 & 3.44 & 3.45 & 3.46 & 3.47 \\
Ca (mg/100g) & 8.05 & 9.84 & 10.2 & 10.55 & 9.19 & 9.44 & 9.64 \\
Energy (K.cal) & 495.46 & 483.2 & 475.3 & 465.7 & 479.42 & 470.82 & 460.78 \\
\hline
\end{tabular}

*Avalable carbohydrates percentage was calculated by the difference.

absorption and retention of water. It was found that the chemical composition of biscuit improved after the wheat flour substitution by hulled and naked malt. The increasing in the chemical component such as proteins, ash, fiber, minerals may due to the inherent content of barley malt used which contribute to these components content of the resulted biscuit. Results in the present study are in agreement with those reported by Izydorczyk and Dexter (2008). The energy of biscuits decreased after wheat flour substitution by barley malt as general tendency regardless barley variety. Moreover, it decreased with increasing the substitution level. The decrease was more higher in case of wheat flour substituted by naked barley malt compared to hulled barley malt. It decreased by $6 \%$ and $7 \%$ at $35 \%$ as level of substitution, respectively compared to biscuit from wheat flour $72 \%$. This may explain by the high fiber content in barley malt particularly from naked barley. 


\section{Physical properties}

Density, hardness and colour of biscuits manufactured using wheat flour $72 \%$ and substituted wheat flour by hulled and naked barley malt were determined. The obtained results showed that biscuit density increased after wheat flour substituted by barley malt regardless the barley variety compared to those from wheat flour 72\%; it increased with increasing the substitution level (Table 7). It increased by about $6 \%$ and $9 \%$ at $35 \%$ substitution level by hulled and naked barley malt, respectively compared to wheat flour $72 \%$. This increasing in biscuit density may due to the variation of chemical composition between the wheat flour $72 \%$ and the blend (substituted wheat flour), mainly due to the high fiber content of blend. At level $25 \%$ of wheat flour substitution by hulled and naked malt, there were insignificant variation in biscuit density for all biscuit samples, a slight increasing of biscuit density was afterward observed; biscuit density of substituted wheat flour by naked barley malt was higher than those from substituted wheat flour from hulled barley malt. The high biscuit density from substituted wheat flour by naked barley malt could be explained by the high fiber content which found in naked barley malt $(23.7 \%)$.

As biscuit hardness, it was found that biscuit hardness increased after wheat flour substitution by barley malt and with increasing the substitution level as well. The highest hardness was recorded for the highest substitution level $(35 \%)$ regardless barley variety (Table 7$)$. It increased by about $34 \%$ and $47 \%$ when wheat flour, substituted by hulled and naked barley malt, respectively compared to that from wheat flour $72 \%$. Biscuit manufactured from substituted wheat flour by naked barley malt was harder than that manufactured from substituted wheat flour by hulled barley malt lowering its acceptability (Table 8). It may due to the high fiber content of naked barley malt $(23.7 \%)$ versus $(19.5 \%)$ in hulled barley malt. These results are in concordance with those obtained by Ames et al. (2006).

Food colour is one of the most important factors affecting consumer acceptance of end product. Concerning biscuit colour parameters; $L^{*}, a^{*}, b^{*}$. It was found that the lightness of biscuits decrease after wheat flour substitution by barley malt, the decreasing was significant for the biscuit manufactured from substituted wheat flour by hulled malt barley especially at $25 \%$ substitution level. It was decreased by about $64 \%$ and $63 \%$, respectively compared to that manufactured from wheat flour $72 \%$ and from substituted wheat flour by naked barley malt. This mean that there was insignificant variation in the lightness between biscuit manufactured from wheat flour $72 \%$ and that manufactured from substituted wheat flour by naked barley malt. Biscuit redness $\mathrm{a}^{*}$ and yellowness $b^{*}$ increased after wheat flour substitution by barley malt with increasing substitution levels regardless the barley, but this increasing was remarkable in case naked barley malt substitution. The changes in colour parameters of biscuit manufactured using substituted wheat flour by barley may due to the variation of chemical composition compared to wheat flour $72 \%$, the colour of malt itself and millard reaction which takes place during baking (Abd El-Hady et al., 2011).

\section{Sensory evaluation}

Sensory evaluation was carried out to define the adequate level of wheat flour substitution by barley malt and to define which variety improved the whole quality of biscuit. The obtained results showed that biscuit manufactured from wheat flour $72 \%$ had the highest score for all sensory characteristics; appearance, colour, taste, flavour and all acceptability, followed by biscuit manufactured from substituted wheat flour at $25 \%$ of hulled and naked barley malt which was close to that manufactured from wheat flour $72 \%$. The lowest score was recorded to the high level of substitution $(35 \%)$ of barley malt particularly hulled barley malt. The sensory evaluation results confirmed the previous results indicating that $25 \%$ as substitution level was adequate level to substitute wheat flour by barley malt according to the physical properties.

\section{Conclusion}

In conclusion, hulled and naked barley malt have some of useful components based on its high content of very easily digested carbohydrates, enzymatically hydrolyzed protein, minerals, dietary fiber and healthy components made it suitable for enriching cereal products. Results from this study clearly showed that hulled and naked barley malt can be used up to 25 and $30 \%$ to enhance nutritional value of biscuits without remarkable effect on its rheological properties and quality parameters without any effects on the other organoleptic attributes. 
Table 7. Physical properties of biscuit manufactured using wheat flour $72 \%$ and substituted wheat flour by hulled and naked barley malt

\begin{tabular}{lccccccc}
\hline & \multicolumn{7}{c}{ Biscuit } \\
\hline Physical property & $\begin{array}{c}\text { Wheat flour } \\
(\mathbf{7 2 \% )}\end{array}$ & \multicolumn{3}{c}{ Hulled barley malt } & \multicolumn{3}{c}{ Naked barley malt } \\
\cline { 3 - 9 } & & $\mathbf{2 5 \%}$ & $\mathbf{3 0 \%}$ & $\mathbf{3 5 \%}$ & $\mathbf{2 5 \%}$ & $\mathbf{3 0 \%}$ & $\mathbf{3 5 \%}$ \\
\hline Density (g. $\left.\mathbf{~ c m}^{-3}\right)$ & 1.52 & 1.57 & 1.59 & 1.61 & 1.56 & 1.61 & 1.65 \\
Hardness (N) & 17.60 & 19.21 & 21.37 & 23.64 & 19.46 & 22.38 & 25.78 \\
$\mathbf{L}^{*}$ & 52.61 & 49.7 & 48.88 & 47.2 & 51.72 & 50.96 & 50.66 \\
$\mathbf{a}^{*}$ & 3.03 & 3.86 & 4.24 & 4.90 & 3.65 & 4.88 & 6.07 \\
$\mathbf{b}^{*}$ & 17.97 & 18.46 & 19.47 & 21.44 & 20.41 & 20.95 & 20.7 \\
\hline
\end{tabular}

L* (Lightness), $a^{*}$ (redness/greenness) and $b^{*}$ (yellowness/blueness).

Table 8. Sensory evaluation of biscuit manufactured using wheat flour $72 \%$ and substituted wheat flour by hulled and naked barley malt

\begin{tabular}{lccccc}
\hline & $\begin{array}{c}\text { Appearance } \\
(\mathbf{1 0})\end{array}$ & $\begin{array}{c}\text { Colour } \\
(\mathbf{1 0})\end{array}$ & $\begin{array}{c}\text { Taste } \\
(\mathbf{1 0})\end{array}$ & $\begin{array}{c}\text { Flavour } \\
(\mathbf{1 0})\end{array}$ & $\begin{array}{c}\text { Over all } \\
\text { acceptability }\end{array}$ \\
\hline Control & $9.13 \pm 0.805$ & $9.2 \pm 0.748$ & $9.13 \pm 0.80$ & $9.2 \pm 0.541$ & $9.41 \pm 0.489$ \\
Hulled Barley & & & & & \\
$\mathbf{2 5 \%}$ & $8.13 \pm 1.024$ & $8.1 \pm 1.24$ & $8.33 \pm 1.14$ & $8.67 \pm 0.869$ & $9.37 \pm 1.24$ \\
$\mathbf{3 0 \%}$ & $8.02 \pm 1.22$ & $8.21 \pm 1.22$ & $8.06 \pm 0.771$ & $8.18 \pm 0.881$ & $8.51 \pm 0.956$ \\
$\mathbf{3 5 \%}$ & $7.93 \pm 1.062$ & $7.93 \pm 1.062$ & $7.75 \pm 1.042$ & $8.25 \pm 1.042$ & $7.38 \pm 1.161$ \\
Naked Barley & & & & & \\
$\mathbf{2 5 \%}$ & $8.2 \pm 1.661$ & $8.2 \pm 1.661$ & $8 \pm 1.316$ & $8.13 \pm 1.087$ & $9.12 \pm 1.087$ \\
$\mathbf{3 0 \%}$ & $8.46 \pm 0.884$ & $8.42 \pm 0.884$ & $8.4 \pm 0.952$ & $8.46 \pm 0.805$ & $9.33 \pm 0.942$ \\
$\mathbf{3 5 \%}$ & $8.33 \pm 1.33$ & $8.06 \pm 1.34$ & $8.1 \pm 1.181$ & $7.93 \pm 0.997$ & $8.6 \pm 1.963$ \\
\hline
\end{tabular}

\section{REFERENCES}

AACC (2007). American Association of Cereal Chemists Approved methods of Analysis. AACC International, st.paul, MN:http// dx. doi. org/10.1094/ AACC Intmethod.

Abbaspour, N., R. Hurrell and R. Kelishadi (2014). Review on iron and its importance for human health. J. Res. Med. Sci., 19 (2): 164-174.
Abd El-Hady, M., Z. Soliman and M.Y. Hafez (2011). Evaluation of some street- vended foods in Egypt. Egypt. J. Appl. Sci., 26 (3): 51-62

Ames, N., C. Rhymer, B. Rossnagel, M. Therrien, D. Ryland, S. Dua and K. Ross (2006). Utilization of diverse hulless barley properties to maximize food product quality. Cereal Foods World, 51: 23-38. 
Amiri, A., Z. Triplett, A. Moreira, N. Brezinka, and C.A. Ulven (2017). Standard density measurement method development for flax fiber. Indust. Crops and Prod., 96:196-202.

AOAC (2005). Official Methods of Analysis of the Association of Official Analytical Chemists, $18^{\text {th }}$ Ed. Gaithersburg, Maryland, USA, AOAC Int.

AOAC (1995). Official Methods of Analysis of AOAC Int., $16^{\text {th }} \mathrm{Ed}$. Methods 992.28 and 995.16.The Association, Arlington, VA.

Behall, K.M., D.J. Scholfield and J. Hallfrisch (2004). Diets containing barley significantly reduce lipids in mildly hypercholesterolemic men and women. Ame. J. Clin. Nut., 80: 1185-1193.

Behall, K.M., D.J. Scholfield and J. Hallfrisch (2005).Comparison of hormone and glucose responses of overweight women to barley and oats. J. Ame. Coll. Nut., 24:182-188.

Behall, K.M., D.J. Scholfield and J. Hallfrisch (2006). Barley $\beta$-glucan reduces plasma glucose and insulin responses compared with resistant starch in men. Nut. Res., $26: 644$ 650.

Campos, D.T., J.F. Steffe and P.K.W. Ng, (1997). Rheological behavior of undeveloped and developed wheat dough. Cereal Chem., (74): 489-494.

Chau, C.F. and Y.-L. Huang (2003). Comparison of the chemical composition and physicochemical properties of different fibers prepared from the peel of Citrus sinensis L. cv. Liucheng. J. Agric. Food Chem., 51: $2615-2618$.

Dominick, S. and R. Derrick (2001). Theory and Problems of Statistics and Econometrics. $2^{\text {nd }}$ Ed. New York, 202.

FAO (2014). http//:www.fao.org.

Garau, M.C., S. Simal, C. Rossello' and A. Femenia (2007). Effect of airdrying temperature on physicochemical properties of dietary fibre and antioxidant capacity of orange (Citrus aurantium v. Canoneta) byproducts. Food Chem., 104:1014-1024.
Hooda, S. and S. Jood (2005). Organoleptic and nutritional evaluation of wheat biscuits supplemented with untreated and treated fenugreek flour. Food Chem., 90: 427-435.

Izydorczyk, M.S., J. Storsley, D. Labossiere, A.W. MacGregor and B.G. Rossnagel (2000). Variation in total and soluble bglucan content in hulless barley: effects of thermal, physical, and enzymic treatments. J. Agric. and Food Chem., 48: 982-989.

Izydorczyk, M.S., S.L. Lagasse', D.W. Hatcher, J.E. Dexter and B.G. Rossnagel (2005). Theenrichment of Asian noodles with fibrerich fractions derived from roller milling of hull-less barley. J. Sci. and Food Agric., 85: 2094-2104.

Izydorczyk, M.S. and J.E. Dexter (2008). Barley $\beta$-glucans and arabinoxylans: Molecular structure, physicochemical properties, and uses in food products. J. Food Res. Int., 11 (45): 850-868.

Mahdi, G.S., M. Abdelal and B. NeerajVerma, A. Sonone and U. Makhija (2008). A review: barley is a healthful food. Food Chem., 7 (13): 2686-2694.

Mareček, V., A. Mikyškab, D. Hampelc, P. Čejkab, J. Neuwirthovád, A. Malachová and R. Cerkala (2016). ABTS and DPPH methods as a tool for studying antioxidant capacity of spring barleyand malt. J. Cereal Sci., 51: 8-11.

Meiselman, H.L. (2016). Quality of life, wellbeing and well-ness: Measuring subjective health for foods and other products. Food Quality and Pref., 54:101-109.

Mesías, M., F. Holgado R. Sevenich, J.C. Brian, G. Marquez-Ruiz and F.J. Morales (2015). Fatty acids profile in canned tuna and sardine after retort sterilization and high pressure thermal sterilization treatment. J. Food and Nutr. Res., 54:171-178.

Mesías, M., H. Francisca, G. Marquez-Ruiz, and J.M. Francisco (2016). Risk/benefit considerations of a new formulation of wheat-based biscuit supplemented with different amounts of chia flour. LWT - Food Sci. and Technol., (73): 528-535. 
Newman, C.W. and R.K. Newman (2006). A brief history of barley foods. Cereal Foods World, 51: 4-7.

Niva, M. (2007). All foods affect health: Understandings of functional foods and healthy eating among health-oriented Finns. Appetite, 48: 384-393.

Pins, J.J. and H. Kaur (2006). A review of the effects of barley b-glucanon cardiovascular and diabetic risk. Cereal Foods World, 51: 8-11.

Quinde, Z., S.E. Ullrich and B.K. Baik (2004). Genotypic variation in colour and discolouration potential of barley-based food products. Cereal Chem., 81: 752-758.

Skendi, A., M. Papageorgiou and C.G. Biliaderis (2009). Effect of barley b-glucan molecular size and level on wheat dough rheological properties. J. Food Eng., (91): 594-601.
Steelea, K., E. Dickinb, M.D. Keerio, S. Samad, C. Kambona, R. Brooka, W. Thomasc and G. Frost (2013). Breeding low-glycemic index barley for functional food. J. Field Crops Res., 154: 31-39.

Sullivan, P., E. Arendt and E. Gallaghera (2012). The increasing use of barley and barley by-products in the production of healthier baked goods. Trends in Food Sci. and Technol., 1-11.

USDA (2004). National Nutrient Database for Standard Reference, Release, 17.

Zenoozian, M.S., S. Devahastin, M.A. Razavi, F. Shahidi and H.R. Poreza (2007). Use of artificial neural network and image analysis to predict physical properties of osmotically dehydrated pumpkin. Drying Technol., 26: 132-144.

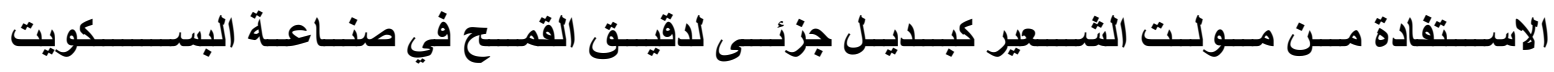

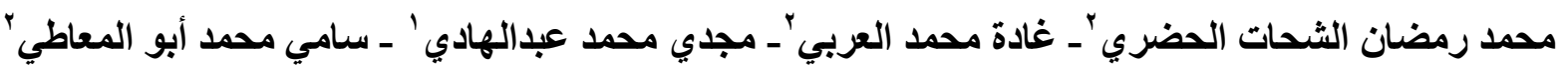

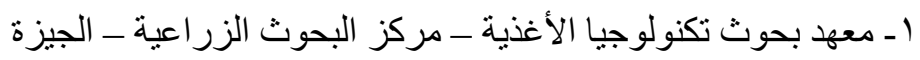

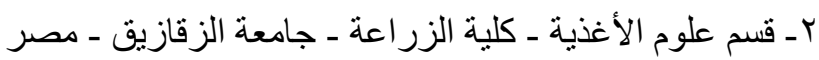

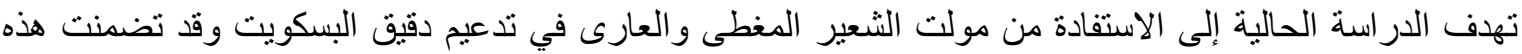

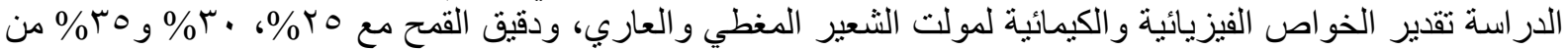

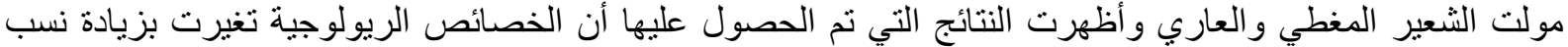

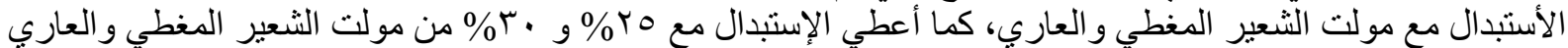

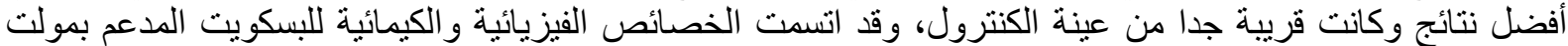

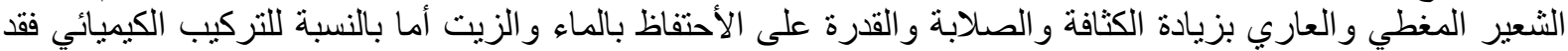

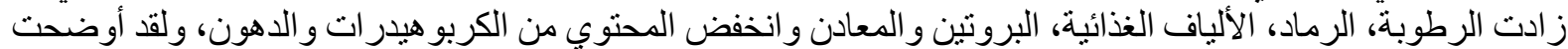

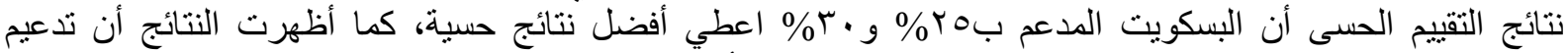

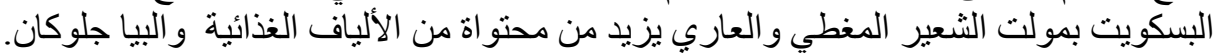

أستاذ الصناعات الغذائية ـ كلبة الزر اعة بمشتهر - جامعة بنها. أستاذ الصناعات الغذائية المتفرغ ع كلية الزر اعة - جامعة الزقازيق. 